\title{
Heat Shock Proteins, microRNAs, and Drug Design Studies in Medicinal Chemistry
}

\section{Yusuf Tutar*}

Basic Pharmaceutical Sciences, Faculty of Pharmacy, Division of Biochemistry, Cumhuriyet University, Sivas, 58140, Turkey

Heat shock proteins (Hsps) are highly conserved chaperone protein family which is responsible for proper folding of newly synthesized and misfolded proteins, cellular signaling, and prevention of protein aggregation. Hsps consist of six major members: small Hsps $(<30 \mathrm{kDa})$, Hsp40 (40 kDa), Hsp60 (60 kDa), Hsp70 (70 kDa), Hsp90 (90 kDa), and Hsp100 $(100 \mathrm{kDa})$. Hsps are found at different parts of the cell (mitochondria, endoplasmic reticulum, cytosol) and their expression level is increased under cellular stress conditions (i.e. malignancy, infection, heavy metals, heat, hypoxia, and oxidative stress). Therefore, expression of high levels of Hsps is related with disease's pathogenesis [1-3]. In our laboratory, we investigate potential roles of Hsps in tumoregenesis and pathogenesis of infection diseases.

Toxoplasmosis is an important infection disease caused by the protozoan Toxoplasma gondii. T. gondii is an ubiquitous obligate intracellular parasite and important member of the apicomplexan phylum/family. T. gondii infects one out of three people in the world, and this infection is observed at immunocompromised individuals such as AIDS patients and pregnant women. These individuals may become seriously ill and the parasite can occasionally cause death. Furthermore, toxoplasmosis causes morbidity and mortality when transmitted during pregnancy. It can cause inflammation of the brain, neurologic diseases, and it also affects the heart, liver, inner ears, and eyes. In humans, the life cycle of T. gondii has two stages: tachyzoite and bradyzoite. Tachyzoite is infective form of T. gondii and causes toxoplasmosis. In later stage of infection, tachyzoites are converted to bradyzoites, and can remain latent in the human tissues [4-6]. Our studies aim to characterize and investigate T. gondii Hsps to understand $T$. gondii survival in the host organism and develop new therapeutic strategies against toxoplasmosis. In an effort, Hsp40, Hsp70, and Hsp100 isolated from infective T. gondii RH strain, and the Hsps expressions are increased during conversion from tachyzoites to bradyzoites. Moreover, inhibition of Hsps suppresses bradyzoite development in host cell $[7,8]$.

Hsps play essential roles in all stages of tumoregenesis. Proteins expose to poor conditions and cellular stresses (oxidative stress, hypoxia) in cancer cells. Hsps are overexpressed in tumors to protect three dimensional structures of oncogenic proteins and provide cellular hemostasis $[9,10]$. Especially, Hsp90 is involved in correct folding, stabilization, and activation of oncogenic proteins, thus apoptosis, angiogenesis, cell proliferation, metastases, and invasion pathways need Hsp90 chaperone activity. Hsp90 is one of the most expressed proteins in normal cells, and its expression can increase up to 10-fold in tumors. Therefore, inhibition of $\mathrm{Hsp} 90$ has been significant therapeutic perspective in cancer treatment $[2,11,12]$. In our study, we synthesized novel thiazolyl coumarine derivatives, and their anti-cancer activities were tested on human liver and colon cancer cell lines. Coumarine is benzopyrone class compounds and especially demonstrates anticancer and antimicrobial activity. Biochemical and in-silico experiments showed that, thiazolyl coumarine derivative compounds inhibited Hsp90 chaperone functions and have important potential to develop new target specific anticancer drugs [13].

Oncogenic kinase enzymes, estrogen receptor alpha (ER- $\alpha)$ and heme oxygenase have been extensively investigated in target specific cancer drug design studies by my research group. Kinase enzymes, including serine-threonine protein kinases, cyclin-dependent kinases, c-Jun N-terminal kinases, are overexpressed in tumor cells and participate in oncogenic signaling pathways [14]. In our recent works, we synthesized novel acyl thiourea derivatives containing pyrazole ring compounds and determined their anticancer activities on leukemia, colon, liver, breast, and bone cancer cell line as potential Aurora kinase inhibitors $[15,16]$. ER- $\alpha$ is an important biological marker around $70 \%$ of breast cancer cases. ER- $\alpha$ actives oncogenic signaling pathways and stimulates proliferation of breast tumors. In order to interrupt breast tumorgenesis, blocking of ER- $\alpha$ is accepted common treatment and preventive strategy, and FDA approved ER- $\alpha$ inhibitors are applied in ER- $\alpha$ positive breast cancer patient [17]. Novel alnustone (a nonphenolic diarylheptanoid) derivative compounds were designed as an ER- $\alpha$ inhibitor by our research group. Anticancer activities of compounds were determined on human ER- $\alpha$ positive invasive ductal breast cancer cell line (MCF-7). According to the experimental results, these compounds exhibited both protective and therapeutic activity by blocking tumorgenesis of human breast cancer cells [18]. Heme oxygenases are signaling molecules which catalyze heme degradation and $\mathrm{CO}$ release. Especially heme oxygenase-1 has cytoprotective properties against cellular stress factors (hypoxia, hydrogen peroxide, and reactive oxygen species). Heme oxygenase- 1 inhibits angiogenesis and triggers apoptosis in cancer cells. Therefore, CO-releasing molecules (CO-RMs) have been designed and synthesized for treatment of cancer and infection diseases in the literature. CORMs supply CO for cancer cells and inhibit several apoptosis and angiogenesis related oncogenic protein, matrix metalloproteinase-9 (MMP9) $[19,20]$. We synthesized novel manganese containing CORMs, and now their anticancer activities are being tested on human breast cancer cell lines.

MicroRNAs (miRNAs) are short (18-22 nucleotide long) noncoding RNA molecules which are involved in gene regulation in normal and cancer cells (http://www.mirbase.org/). Human tumors are regulated by miRNA expression levels, claimed as oncogene and/or tumor suppressor. miRNAs defined as major regulators of coding genes in genome and are new agents that is employed in diagnosis, prognosis and gene targeting at therapeutic biomarkers in pharmacology. miRNAs inhibit tumoregenesis and play key roles in regulation of cancer metastasis. Furthermore, miRNAs are essential in

*Corresponding author: Yusuf TUTAR, Cumhuriyet University, Faculty of Pharmacy, Basic Pharmaceutical Sciences, Division of Biochemistry, Sivas, 58140, Turkey; Tel: 90346 2191010; E-mail: ytutar@cumhuriyet.edu.tr

Received May 01, 2015; Accepted May 27, 2015; Published May 29, 2015

Citation: Tutar Y (2015) Heat Shock Proteins, microRNAs, and Drug Design Studies in Medicinal Chemistry. Single Cell Biol 4: 112. doi:10.4172/21689431.1000112

Copyright: (c) 2015 Tutar Y. This is an open-access article distributed under the terms of the Creative Commons Attribution License, which permits unrestricted use, distribution, and reproduction in any medium, provided the original author and source are credited. 
Citation: Tutar Y (2015) Heat Shock Proteins, microRNAs, and Drug Design Studies in Medicinal Chemistry. Single Cell Biol 4: 112. doi:10.4172/21689431.1000112

Page 2 of 2

biological processes such as cell progression, differentiation, growth, and apoptosis. Therefore, there is a growing interest in anti-cancer therapeutic research at recent years [21-23]. My research group focuses on the relationship between miRNA expression and cancer prognosis in human cancer cell lines. Moreover; the effect of miRNA expression on Hsps regulation is investigated in tumorgenesis. In our previous paper, relationships between HSP isoforms with miRNAs were determined on NCI-60 breast cancer cell lines by using Cell Miner analysis tool [24].

Research at molecular level promotes innovative outcomes and my research is focused on biochemical pathways to elucidate molecular mechanisms.

\section{References}

1. Tutar L, Tutar $Y$ (2010) Heat shock proteins; an overview. Curr Pharm Biotechnol 11: 216-222.

2. Ozgur A, Tutar $Y(2014)$ Heat shock protein 90 in oncology. Curr Proteomics 11(2): 2-16.

3. Ciocca DR, Calderwood SK (2005) Heat shock proteins in cancer: diagnostic, prognostic, predictive, and treatment implications. Cell Stress Chaperones 10: 86-103.

4. Kim K, Weiss LM (2008) Toxoplasma: the next 100 years. Microbes Infect 10: 978-984.

5. Contreras-Ochoa CO, Lagunas-Martínez A, Gerson JB; Correa D Toxoplasma gondii invasion and replication in astrocyte primary cultures and astrocytoma cell lines: systematic review of the literature. Parasitol Res 110(6): 2089-2094.

6. Lyons RE, McLeod R, Roberts CW (2002) Toxoplasma gondii tachyzoitebradyzoite interconversion. Trends Parasitol 18: 198-201.

7. Coskun KA, Ozgür A, Otag B, Mungan M, Tutar $Y$ (2013) Heat shock protein 40-Gok1 isolation from Toxoplasma gondii RH strain. Protein Pept Lett 20: 1294-1301.

8. Co̊̊Ÿkun KA, Tutar Y (2015) Isolation and characterization of Heat Shock Protein 100-Batu1 from Toxoplasma gondii RH strain. Exp Parasitol 153: 91-97.

9. Trepel J, Mollapour M, Giaccone G, Neckers L (2010) Targeting the dynamic HSP90 complex in cancer. Nat Rev Cancer 10: 537-549.
10. Jego G, Hazoumé A, Seigneuric R, Garrido C (2013) Targeting heat shock proteins in cancer. Cancer Lett 332: 275-285.

11. Li J, Soroka J, Buchner J (2012) The Hsp90 chaperone machinery: conformational dynamics and regulation by co-chaperones. Biochim Biophys Acta 1823: 624-635.

12. Sidera K, Patsavoudi E (2014) HSP90 inhibitors: current development and potential in cancer therapy. Recent Pat Anticancer Drug Discov 9: 1-20.

13. Koca I, Gümüs M, Özgür A, Disli A, Tutar Y (2015) A novel approach to inhibit heat shock response as anticancer strategy by coumarine compounds containing thiazole skeleton. Anticancer Agents Med Chem. In Press.

14. Zhang J, Yang PL, Gray NS (2009) Targeting cancer with small molecule kinase inhibitors. Nat Rev Cancer 9: 28-39.

15. Koca İ, Özgür A, Coşkun KA, Tutar Y (2013) Synthesis and anticancer activity of acyl thioureas bearing pyrazole moiety. Bioorg Med Chem 21: 3859-3865.

16. Ozgur A, Yenidunya E, Koca I, Tutar Y (2015) Acyl thiourea derivatives containing pyrazole ring selective targeting of human aurora kinases in breast and bone cancer. Lett Drug Des Discov 12: 180-189.

17. Ali S, Coombes RC (2000) Estrogen receptor alpha in human breast cancer occurrence and significance. J Mammary Gland Biol Neoplasia 5: 271-281.

18. Kücükoglu K, Secinti H, Ozgur A, Secen H, Tutar Y (2015) Synthesis, molecular docking, and antitumoral activity of alnustone-like compounds against estrogen receptor alpha-positive human breast cancer. Turk J Chem 39: 179-193.

19. Sunamura M, Duda DG, Ghattas MH, Lozonschi L, Motoi F, et al. (2003) Heme oxygenase- 1 accelerates tumor angiogenesis of human pancreatic cancer Angiogenesis 6: 15-24

20. Was H, Dulak J, Jozkowicz A (2010) Heme oxygenase-1 in tumor biology and therapy. Curr Drug Targets 11: 1551-1570.

21. Tutar L, Tutar E, Tutar $Y$ (2014) MicroRNAs and cancer; an overview. Curr Pharm Biotechnol 15: 430-437.

22. Calin GA, Croce CM (2006) MicroRNA signatures in human cancers. Nat Rev Cancer 6: 857-866.

23. Hayes J, Peruzzi PP, Lawler S (2014) MicroRNAs in cancer: biomarkers, functions and therapy. Trends Mol Med 20: 460-469.

24. Ozgur A, Tutar L, Tutar Y (2014) Regulation of Heat Shock Proteins by miRNAs in human breast cancer. Microrna 3: 118-135. 